\title{
P-0400- Side-effect profile of SGLT2 inhibitors in patient diabetes at a tertiary care center in India
}

\author{
Sujeet Jha, Swati Waghdhare, Manju Panda, Bombee Kumari, \\ Samreen Siddiqui, Nandini Chhabra, Amit Bhargava \\ Institute of Endocrinology, Diabetes \& Metabolism, Max Healthcare Institute Ltd.
}

\section{INTRODUCTION}

Sodium-glucose co-transporter (SGLT) 2 inhibitors are the newest oral hypoglycemic agents in the market. With proven efficacy, they have found their place in clinical therapy as per the ADA/EASD guidelines. Glucose transportation in the body is mainly mediated by two types of transporters: sodium glucose linked transporters (SGLT) and facilitative glucose transporters (GLUTs). SGLT are the members of sodium substrate cotransporters, the solute carrier family 5A (SLC5A). Sodiumglucose co-transporter-2 inhibitors work by inhibiting SGLT2 in the PCT, to prevent reabsorption of glucose and facilitate its excretion in urine.

\section{MATERIALS \& METHODS}

- It was a retrospective study, conducted over a period of 12 months (2015-16).

- We retrospectively analyzed the data of 100 patients diagnosed with type 2 diabetes mellitus (T2DM), who were put on a SGLT2 inhibitor (Canagliflozin 100mg (61\%)/Empagliflozin 10mg (1\%)/Dapagliflozin 10mg (38\%) once daily), in addition to their ongoing glucose lowering therapy.

- The side effect profile/adverse event rate was assessed via a questionnaire/telephonic follow-up.

\section{RESULTS}

- Data of 100 patients was analyzed. Mean age was $52.41 \pm 10.05$ years

- $33 \%$ were females and $67 \%$ males. Average BMI was $23.91 \pm 13.89 \mathrm{~kg} / \mathrm{m}^{2}$. Baseline weight was $85.85 \pm 18.71 \mathrm{~kg}$ and HbA1c was $7.1 \pm 3.96 \%$. At 6 months, average weight dropped to $79.77 \pm 22.87 \mathrm{~kg}$ and $\mathrm{HbA} 1 \mathrm{c}$ to $56 \pm 3.15 \%$. (Table 1)

- In the overall cohort, 13 patients reported developing Genitourinary symptoms after 1 month of therapy or taking antibiotics as prescribed by General Practitioner and 7 patients after 3 months.

- By the end of 6 months 23 patients had stopped the drug (Figure 3), at different time points. Of this, $69.5 \%$ felt that they should stop due to no defined reason, without consultation of a physician. $21.7 \%$ stopped due to a Genitourinary symptom (Figure 4). One patient reported balanitis and one reported vaginitis. No cases of euglycemic DKA and hypoglycemia were seen (Figure 2).

\begin{tabular}{|c|c|c|c|}
\hline & Baseline & After 3 Months & $\begin{array}{c}\text { After 6 } \\
\text { Months }\end{array}$ \\
\hline $\begin{array}{c}\mathrm{BMI} \\
\left(\mathrm{Kg} / \mathrm{m}^{2}\right)\end{array}$ & $29.61 \pm 8.4$ & $28.60 \pm 8.2$ & $27.6 \pm 7.8$ \\
\hline $\begin{array}{c}\text { Weight } \\
(\mathrm{Kg})\end{array}$ & $85.85 \pm 18.71$ & $82.67 \pm 24.75$ & $79.77 \pm 22.87$ \\
\hline HbA1c $(\%)$ & $7.10 \pm 3.96$ & $7.38 \pm 1.01$ & $5.56 \pm 3.15$ \\
\hline
\end{tabular}

Table 1: Clinical parameters of study population at baseline and follow-up
As glucose is excreted, its plasma levels fall leading to an improvement in all glycemic parameters (Figure 1). This mechanism of action is dependent on blood glucose levels and, unlike the actions of thiazolidinediones (mediated through GLUTs), is independent of the actions of insulin. Thus, there is minimal potential for hypoglycemia, and no risk of overstimulation or fatigue of the beta cells.



Figure 2: Side-effect profile
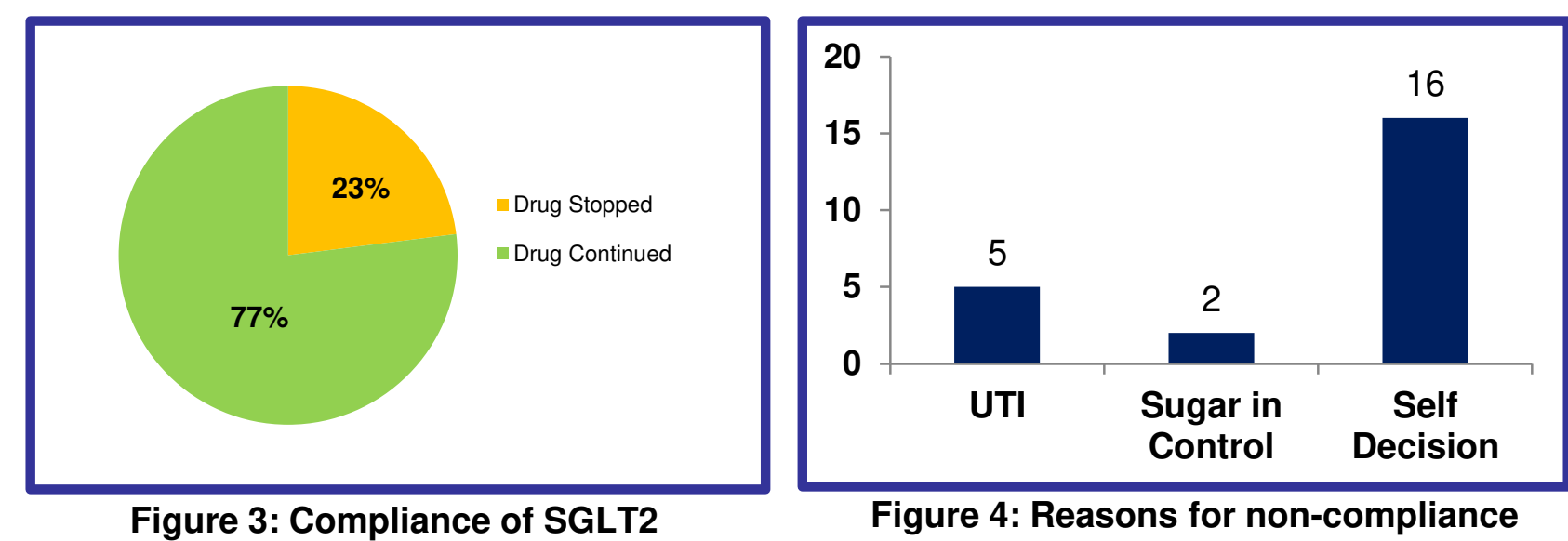

\section{CONCLUSION}

SGLT2 is a new class of drugs in India. We had large drop-outs of SGLT2, which could be primarily due to perceived UTI and medicine cost. The cases of genito-urinary infection in patients were higher than as reported in clinical trials, this drug should be used cautiously in such patients.

\section{REFERENCES}

1. Kanai $\mathrm{Y}, \mathrm{Lee} \mathrm{WS}$, You $\mathrm{G}$ et al. The human kidney low affinity $\mathrm{Na} /$ glucose cotransporter SGLT2: delineation of the major renal reabsorptive mechanism for D-glucose. J ClinInvestig.1994; 93:397404.

2. Nauck MA. Update on developments with SGLT2 inhibitors in the management of type 2 diabetes. Drug Des Devel Ther. 2014;8:13351380. 